\title{
Study on the Characteristics, Functions and Development Path of Green Logistics
}

\author{
Shengxian Duan \\ Hunan Modern Logistics College \\ Changsha, China 410131
}

\begin{abstract}
With the development of modern logistics and people's increasing awareness of environmental protection, green logistics has attracted more and more attention from society and government departments. Starting from the development background of green logistics, this paper analyses the five characteristics and functions of green logistics, and puts forward the development path of green logistics from the micro and macro levels.
\end{abstract} path

Keywords-green logistics; characteristics; role; development

\section{INTRODUCTION}

Green logistics refers to restraining the harm of logistics to the environment while realizing the purification of logistics environment and making the best use of logistics resources. The goal of green logistics is to introduce environmental management into all systems of logistics industry, strengthen environmental management and supervision of various operation links in logistics industry, such as storage, transportation, packaging, handling, circulation and processing, and effectively curb pollution and energy waste caused by logistics development. Specifically, the goal of green logistics is different from general logistics activities. General logistics activities are mainly to achieve the profit of logistics enterprises, meet customer needs, expand market share and so on. These goals are ultimately to achieve the economic interests of a certain subject. In addition to pursuing the above economic interests, green logistics also pursues the goal of saving resources and protecting the environment, which has both economic and social attributes. Green logistics must follow the principle of unification of economic interests, social interests and environmental interests in order to achieve sustainable development as the ultimate goal.

\section{BACKGROUND OF GREEN LOGISTICS DEVELOPMENT}

Modern logistics plays an increasingly obvious role in the development of our economy, but at the same time it also brings a series of social problems, which are mainly manifested in the fact that all aspects of modern logistics activities cause pollution to the environment to varying degrees.

\section{A. Environmental Pollution in Transportation Process}

The environmental pollution in the transportation process is mainly manifested in three aspects: first, the serious environmental pollution caused by the exhaust gas of the transportation vehicles in the transportation process, and even the severe haze weather in some cities; second, the noise pollution caused by the transportation vehicles in the transportation process; third, the various origins of the goods transported. Leakages cause damage to the environment, such as oil leaks during land and water transportation, which lead to large areas of land or water pollution, which is harmful, time-consuming and difficult to recover.

\section{B. Environmental Pollution During Storage and Storage}

The main environmental pollution caused by storage and storage are as follows: first, using chemical methods to maintain the stored goods, such as spraying disinfection, insecticides and fungicides, polluting the surrounding ecological environment; second, improper storage of stored goods, leading to the expiration and abandonment of goods, resulting in environmental pollution; third, toxic, flammable and explosive. The improper storage of dangerous chemicals, explosion or leakage, will also pollute and damage the surrounding environment.

\section{Environmental Pollution from Circulation Processing}

Environmental pollution caused by circulation processing: on the one hand, due to the lack of scientific planning before processing, excessive resources are consumed in processing, which brings negative effects to the natural environment; on the other hand, the waste gas, wastewater, waste and noise produced by processing all pose a hazard to the environment and human body.

\section{Environmental Pollution of Packaging}

Packaging pollution to the environment is mainly manifested in two aspects: on the one hand, waste incineration of packaging materials pollutes the environment; on the other hand, brutal handling in the process of ecommerce logistics leads to excessive packaging or duplicate packaging, resulting in waste of resources and increasing the burden of the environment. 
Through preferential tax policies and financial support, the state can establish demonstration zones of circular logistics and guide the orderly development of circular logistics.

\section{E. Sustainability}

Traditional logistics is extensive in the use of resources, resulting in more waste of resources; therefore, the development of green logistics, saving resources and protecting the environment will become an important contribution of the logistics industry to the sustainable and harmonious development of human society.

\section{THE ROLE OF GREEN LOGISTICS}

Green logistics is not only of great significance to environmental protection and sustainable economic development, but also brings enormous economic benefits to enterprises.

\section{CHARACTERISTICS OF GREEN LOGISTICS}

Compared with traditional logistics, green logistics has the following characteristics.

\section{A. Symbiosis}

Green logistics pays attention to the coexistence of environmental protection and economic development. By improving the level of logistics management and adopting advanced logistics technology and equipment, we can reduce or eliminate the negative impact of logistics on the environment and realize the common development and progress of logistics and environment.

\section{B. Economy}

Green logistics pays attention to saving resources. There are different degrees of waste of resources in the process of logistics circulation of various social materials. To save resources and alleviate environmental pressure needs to adopt legal and economic means to guide enterprises to implement resource conservation in place.

\section{Low Entropy}

Entropy is an irreversible process in which the effective energy decreases but the effective energy increases in a closed system. Low-Entropy Logistics is mainly manifested in green low-energy logistics, which requires JIT production, lean manufacturing and other advanced management methods to reduce inventory, and joint distribution and optimization of transportation routes to reduce distribution energy consumption.

\section{Cyclicity}

Compared with traditional logistics, green logistics pays more attention to how to achieve efficient, environmentally friendly and energy-saving circular logistics. Recycling logistics includes recycling of raw materials and by-products, packaging recycling, waste recycling, resource garbage collection and recycling, etc. At present, China's circulation logistics operation lacks effective management system, management mode and policy guidance mechanism.

\section{A. Favorable to Reduce Waste Generation}

Consumption of resources and energy, accompanied by the process of logistics activities, will also bring pollution to the environment. Implementing green logistics requires enterprises to grasp the environmental situation, pay attention to environmental protection, reduce pollution, pay attention to energy conservation, reduce consumption and reduce costs. This requires enterprises to improve the level of resource management and management capabilities, form a systematic management mechanism, reduce waste generation, and promote the coordination and sustainable development of enterprise environment and economy.

\section{B. Favorable to Reduce Social Logistics Cost}

In 2017, the ratio of the total cost of social logistics to GDP was $14.6 \%$, which was 3.4 percentage points lower than that in 2012, and realized the "five consecutive declines". However, it is noteworthy that the ratio of total logistics cost to GDP in China is still higher than the average level of major developed countries, which reflects that the problem of "high cost and low efficiency" of logistics in China is still prominent. The implementation of environmental protection and energy-saving treatment in logistics industry forces enterprises to optimize logistics system, improve logistics efficiency and save energy, thereby reducing social logistics costs, reducing environmental costs and achieving significant economic benefits.

\section{Favorable for Enterprises to Break Green Trade Barriers}

Green logistics can break down the green trade barriers established by developed countries. With the development of economic globalization, some traditional tariff and non-tariff barriers are gradually weakening, and green trade barriers are gradually rising. Green trade barriers are governed by a wider range of objects. They not only put forward green environmental protection requirements for products themselves, but also design and development of products, input of raw materials, mode of production, packaging 
use of warehouse area and warehouse volume; Develop or introduce efficient warehousing business management system, optimize the warehousing business process, improve the efficiency of warehousing operations; adopt "five-oriented" stacking, photoelectric identification system and other effective monitoring and counting methods to improve the accuracy of warehousing operations.

3) Green circulation processing: We should make overall arrangements for circulation and processing, guide the development of circulation and processing towards centralization, specialization and scale, make full use of corner wastes, improve the efficiency of resource utilization, and reduce environmental pollution.

4) Green handling: Improving handling efficiency, eliminating invalid handling and improving handling activity; standardizing handling operation, reducing leakage and damage, and eliminating dust; collecting pollutants generated in the unloading process in time, and handling them in accordance with relevant regulations.

5) Green packaging: Packaging materials and printed matter should be harmless to human body and environment, and environmental protection packaging materials should be preferentially selected; product packaging quality and packaging container quality should meet the requirements of GB/T 12121; according to the priority order of green performance contribution of packaging products, resource attribute indicators should consider reduction and appropriate packaging, reuse and recycling.

6) Green distribution: We should carry out centralized and joint distribution, encourage specialized integrated warehouse allocation, improve distribution efficiency and alleviate traffic congestion, and encourage the construction of logistics distribution terminals and public self-service containers with multi-functions such as cargo collection, retail and convenience services.

7) Green information processing: Encourage enterprises to develop and adopt efficient and energy-saving logistics information management system, optimize the structure and process of logistics system, achieve paperless information transmission and audit, improve logistics operation efficiency and reduce logistics costs.

\section{B. Macro Green Logistics}

Macroscopic green logistics refers to the rational layout planning of the industrial development of the whole country, region or city, reducing duplicate logistics activities, improving the efficiency of social logistics and reducing the cost of social logistics; encouraging the adoption of green logistics technology, establishing sound standard rules and regulations and green logistics evaluation system, and standardizing logistics enterprises. Environmental behavior restrains the impact of logistics on the environment from technology and management; vigorously develop waste logistics and recycling logistics, make it standardized and industrialized, and ultimately achieve the coordination and sustainable development of logistics and social economy. technology to ensure the quantity and quality of inventory; rationally plan the internal layout of warehouse, make full 


\section{CONCLUSION}

Green logistics embodies the 3R principle: Reduce, Reuse and Recycling. It can realize the co-development of logistics activities based on effective material circulation with environment, economy and society, minimize the amount of waste in the process of social development, and make waste resources and harmless.

\section{REFERENCES}

[1] Liu Zhanyu, Sun Xialing. Spatial-temporal evolution and motivation analysis of green total factor productivity in China's logistics industry (J). China Electric Power Education, 2018 (4): 77-81

[2] Ke Jinglin, Jiang Weijun, Yang Xingrui. Comparison and Experience of Green Logistics Development Gap between China and Japan (J). Foreign Economic and Trade Practice, 2018 (12): 87-91

[3] Liu Bo. Logistics industry integration characteristics, motivation and mode based on green economy (J). Business economy research, 2019 (6): 95-97.

[4] Liu Xiuhong. Analysis of Logistics Industry Integration Model from the Perspective of Green Economy (J). Business Economy Research, 2019 (8): 98-100.

[5] Zhang Jingjing. Problems and Countermeasures of Fuzhou green logistics development (J). China Management Informatization, 2019 (8): 146-148

[6] Zhao Mingmei. Research on the Development of Urban-Rural Twoway Circulation Cold Chain Logistics under the Guidance of Green Development Concept (J). Price Monthly, 2019 (5): 62-72

[7] Yang Haitao. Study on the Construction Scheme of Green Logistics System in Tianjin (J). Railway Transportation and Economy, 2019 (7): $1-7$. 